\title{
Applying the TOPSIS Approach for Selecting the Best Small Project
}

\author{
Sawsan Sabeeh Al-Zubaidy, Esraa Ibrahiem Al-Bayati \\ Production \& Metallurgy Department, University of Technology, \\ **Corresponding author, esraabayat@yahoo.com, sawsanaa2006@gmail.com \\ Submitted: $17 / 5 / 2017$ \\ Accepted: $\quad 8 / 8 / 2018$
}

\begin{abstract}
Projects selection is a significant problem. However, regularly challenging task. It is difficult because there is typically more than one measurement of the effects on all projects, particularly when there are multiple decision-makers. In this paper, the authors consider a tangible presentation of projects choosing for a different number of projects through an experts opinions by a group decision-making method called TZOPSEIS (Technique for Order Preference by Similarity to an Ideal Solution). This method is characterized by its ability to measure the relative performance for each alternative in a simple mathematical form. Four criteria have been deliberated to select the finest one among five projects and rank them. The proposed manner is used in a case study in the Iraqi environment which is analyzed from diverse directions of vision to evaluate and select the best small project.
\end{abstract}

\section{Keywords: Small Projects, TOPSIS, MCZDM}

1. INTRODUCTION

The project is an impermanent work assumed to produce a unique service, product, or outcome. Impermanent means that each project has a certain finish, and this completion has done when the objectives of the project have been achieved. Otherwise, it comes to be sure that projects' objectives will not or cannot be encountered, or else the necessity for the project no lengthier be existent, and the project is sacked. Impermanent not necessarily means undersized in time, many projects take some years. Conversely, the project's period is determinate. The project is not continuing labors. The selection amongst a set of probable projects or alternates represents a hard mission that judgment creator has to challenge. Project evaluation and selection challenge decisions that are dangerous to the profitability, growing and survival of project administration governments in the progressively competitive international set [1]. These decisions are frequently difficult because they need documentation, thoughts, and exploration of many noticeable and unnoticeable issues. Hwong \& Yoon define many decisions creating as tails: Multiple decisions making is practical to desirable choices (such as evaluation, find importance, and selection) among accessible categorized alternates by multiple characteristics (also typically reverse). One of the two following approaches commonly used for making the decision[2] :

1) Test and Fault approach

2) Modeling approach

In test and fault technique decisions makers aspects, the truth so they elect one of the alternatives and observe the results. When the decision faults are excessive and reason some harms, they transform the choice and choose other alternates. In the second approach, decision-makers model the actual problem and identify elements and their result on each other and contract through the ideal breakdown and prediction of the actual problem. Several measured software development approaches established for defining project choice problematics [3]. Many previous research has presented different techniques and methods of the evaluation and selection of the optimal alternative. (Eddie Cheng and Heng Li 2005) demonstrated an example using a multi-criteria decision-making model to illustrate how to empirically prioritize a set of projects. It is relevant to both industry practitioners and researchers. Industry practitioners adopted the weighted criteria and applied the ANP (Analytical Hierarchy Process) for the direct project selection while (S. Mahmoodzadeh,J. Shahrabi, M. Pariazar, and M. S. Zaeri2007) used fuzzy AHP and the TOPSIS technique for the project selection problem. After reviewing four common methods of comparing alternatives investment, net present value, rate of return, benefit and cost analysis, and payback period. They use them as criteria in AHP tree where firstly, this work has tried to calculate the weight of each criterion. Then by implementing the TOPSIS algorithm, the assessment of the projects has been done. This research is distinguished by using the Delphi Method (it is a technique for collecting data/opinions from experts where these opinions are summarizing, analyzing and reporting) for collecting criteria weights and then applying the TOPSIS technique to obtain projects final ranking. The reason for choosing the Delphi Method is that experts' opinions from the same working environment help in achieving the nearest results to the best accuracy. 
2. TOPGSIS APPROACH [4,5]

TOZAPSZIS (the Technique for Order Preference by Similarity to Ideal Solution) was established by (Hwang and Yoon, 1981). The essential concept of this technique is that the selection of alternates should have the straight space from the idyllic solution and the furthermost space from the negative-idyllic solution in a geometrical sense. This approach deliberates three categories of constructions or criteria:

- Qualitative criterion

- Quantitative criterion

- Budget criteria

As well as dualistic simulated alternatives were assumed:

1) Idyllic alternates: is the alternate which has the finest level for all attributes considered.

2) Destructive alternates: it is the poorest attribute values.

TOAPSIS chooses the alternative that is the closest to the idyllic solution and furthermost from the negative idyllic alternative. TOPSASIS supposes that we have $\mathrm{mm}$ alternatives (choices) and $\mathrm{nn}$ characteristics or criteria and we have the grade of every option with reverence to every criterion [6]. Supposing xij score of option i with reverence to criteria $\mathrm{j}$, we have a matrix $\mathrm{j} X=(\mathrm{xij}) \mathrm{m} * \mathrm{n}$ matrix.

If $\mathbf{J}$ be the set of assistance attributes or criterion (the more is superior), and $\mathrm{J}^{\prime}$ be the set of negative criterion or attributes (fewer is well)

The TOPSIS procedure consists of the following steps (Chen \& Hwang 1992) [7].

Stage 1: Create the normalized decision matrix

This stage transmutes numerous attributes dimensions into non-dimensional elements, which permits appraisals crossways criteria. Normalize scores or data as follows:

$$
r i j=\frac{x i j}{\sqrt{\sum_{i=1}^{m} x_{i j}^{2}}}
$$

rij $=$ The normalize value .

$\mathrm{x}=$ Numerous attributes dimension

$\mathrm{i}=$ No. of alternatives where $\mathrm{i}=1, \ldots, \mathrm{m}$

$\mathrm{j}=$ No. of criterions where $\mathrm{j}=1, \ldots, \mathrm{n}$

Stage 2: Build the normalized weighted decision matrix.

By supposing there were a set of weights for every criterion wj for $j=1, \ldots, n$. , multiply every column in the normalized decision matrix with its related weight. The component of the new matrix is:

$$
V_{i j}=w i j \cdot r i j
$$

Vij $=$ Normalized weighted value

Wij= Criterion weight

Stage 3: Decide the idyllic and negative idyllic solutions.

Idyllic solution:

$$
\begin{gathered}
\boldsymbol{A}^{*}=\left[v 1^{*}, \ldots, v n^{*}\right] \\
\boldsymbol{V}_{\boldsymbol{i j}}=\left[\max (v i j) \text { if } j \in J ; \min (v i j) \text { if } j \in J^{\prime}\right.
\end{gathered}
$$

Where $\mathrm{J}$ is associated with the benefit criteria, and $\mathrm{J}$ ' is associated with the cost criteria.

Negative idyllic solution:

$$
\begin{gathered}
\boldsymbol{A}^{\prime}=\left[v 1^{\prime}, \ldots, v n^{\prime}\right] \\
\boldsymbol{V}^{\prime}{ }_{i j}=\left[\max (v i j) \text { if } j \in J ; \min (v i j) \text { if } j \in J^{\prime}\right.
\end{gathered}
$$

Stage 4: Determine separation rations to each alternate.

Separation from the ultimate alternate computed:

$$
\boldsymbol{S}_{i}^{*}=\sqrt{\sum_{j=1}^{n}\left(v_{i j}-v_{j}^{+}\right)^{2}} \quad i=1,2, \ldots, m
$$

Correspondingly separation commencing the negative ultimate alternate computed:

$$
\boldsymbol{S}_{\boldsymbol{i}}^{*}=\sqrt{\sum_{j=1}^{n}\left(v_{i j}-v_{j}^{-}\right)^{2}} \quad i=1,2, \ldots, m
$$


Stage 5 : Calculate relation nearness to ultimate result :

$$
C * i=\frac{S^{\prime} i}{\left(S * i+S^{\prime} i\right)}
$$

$\mathrm{C}^{* \mathrm{i}}=$ Relation nearness to ultimate result

Stage 6: Sorting the alternates priorities

The superlative mollified alternate now could be agreed conferring to the preference sort direction of $\mathrm{C} * \mathrm{ii}$. Thus, the finest alternates which make the least expanse to the ultimate result. The alternates correlation exposes that somewhat alternate which ensures the minimum expanse to the ultimate solution is located to have the extensive expanse to the ultimate negative result. Lastly, the result that has to be elected the choice by ca*ii closet to one.

\section{The Proposed Procedure}

The selection of the finest small project in the middle of wholly suggested, it is very important and necessary to pick out distinctive conditions (criterion) which could support to catch the finest alternate. The selected criterion for this procedure:

Duration required establishing a project: The duration of the project must be determined. The shorter duration is a project that has higher feasibility where the faster operation after the construction starts to achieve the income.

Raw Materials and Infrastructure: presenting the necessary raw materials to run the project and provide the necessary infrastructure in the site (water, electricity, fuel, lines of communication, transportation, etc.).

Project Risk: Potential risks that may result in a failure of the project or a decrease in profits ( the possibility of damage to raw materials due to exposure to certain environmental conditions, or the validity of the products of the project is short and this may cause a significant loss if the products cannot be marketed).

Expected profits and Return on Investment: The project shall be able to achieve an acceptable profit rate and this percentage must be acceptable. Otherwise, the project is not feasible.

When all criteria are identified, the researchers used Delphi Method. Three professionals assist in laying down the criterion weight reverence for each project. Comparative significance valuations were calculated using a measure of one to nine, wherever the mark of one(1) characterizes too little midst the dualistic elements, as well as the mark of nine (9), specifies that any element is the highest from the other.

4. PRACTICAL APPLICATION

This study has demonstrated a proposal for valuation and choosing of the small project in Iraqi provinces. There are five projects with four different criteria, as shown in Table (4-1).

Table (4-1) The Alternatives and Criteria

\begin{tabular}{|c|c|c|}
\hline No. & Alternatives(projects) & Criteria \\
\hline 1 & Dates piston factory & $\begin{array}{c}\text { Duration required } \\
\text { establishing a project }\end{array}$ \\
\hline 2 & Water filling factory & Raw materials \\
\hline 3 & Dairy factory & Project risk \\
\hline 4 & Plastic factory & $\begin{array}{c}\text { Expected profit and return } \\
\text { on investment }\end{array}$ \\
\hline 5 & Biscuit factory & \\
\hline
\end{tabular}

Table (4-2) illustrates the decision matrix. 
Table (4-2) Decision Matrix

\begin{tabular}{|l|l|l|l|l|}
\hline Wieght & 0.175 & 0.425 & 0.175 & 0.225 \\
\hline
\end{tabular}

\begin{tabular}{|l|c|c|c|c|}
\hline & Criteria 1 & Criteria 2 & Criteria 3 & Criteria 4 \\
\hline Project 1 & 7 & 21 & 4 & 7 \\
\hline Project 2 & 7 & 24 & 6 & 4 \\
\hline Project 3 & 14 & 25 & 3 & 8 \\
\hline Project 4 & 14 & 26 & 9 & 3 \\
\hline Project 5 & 21 & 35 & 4 & 4 \\
\hline
\end{tabular}

Three professionals assist in laying down the criterion weight reverence for each project. Comparative significance valuations were calculated using the measure of one to nine, wherever the mark of one (1) characterizes too little between the two elements as well as the mark of nine (9) specifies that any element is the highest from the other. Normalized weighted matrix is built in Table (4-3).

Table (4-3) Weighted Normalized Matrix

\begin{tabular}{|l|c|c|c|c|}
\hline & Criteria 1 & Criteria 2 & Criteria 3 & Criteria 4 \\
\hline Project 1 & 1.225 & 8.925 & 0.7 & 1.575 \\
\hline Project 2 & 1.225 & 10.2 & 1.05 & 0.9 \\
\hline Project 3 & 2.45 & 10.625 & 0.525 & 1.8 \\
\hline Project 4 & 2.45 & 11.05 & 1.575 & 0.675 \\
\hline Project 5 & 3.675 & 14.875 & 0.7 & 0.9 \\
\hline
\end{tabular}

Table (4-4) The Distances from the Ideal Solution

\begin{tabular}{|c|c|c|}
\hline & $\begin{array}{c}\text { The separation } \\
\text { of alternatives } \\
\text { to positive ideal } \\
\text { one }\end{array}$ & $\begin{array}{c}\text { The separation } \\
\text { of alternatives } \\
\text { to negative ideal } \\
\text { one }\end{array}$ \\
\hline Project 1 & 0.107805 & 0.124281 \\
\hline Project 2 & 0.107805 & 0.090785 \\
\hline Project 3 & 0.096981 & 0.122181 \\
\hline Project 4 & 0.105379 & 0.112779 \\
\hline Project 5 & 0.141766 & 0.083486 \\
\hline
\end{tabular}

The final ranking of projects with respect to the ideal solution is shown in Table (4-5): 
Table (4-5) Projects Final Ranking

\begin{tabular}{|l|c|c|}
\hline & $\begin{array}{c}\text { The relative } \\
\text { closeness } \\
\text { of alternatives } \\
\text { to positive ideal }\end{array}$ & Rank \\
\hline Project 1 & 0.533321 & 2 \\
\hline Project 2 & 0.090785 & 5 \\
\hline Project 3 & 0.61344 & 1 \\
\hline Project 4 & 0.485436 & 3 \\
\hline Project 5 & 0.425865 & 4 \\
\hline
\end{tabular}

\section{DISCUSSION}

The research tests a profit maximization project election and planning problem. However narrow offered supplies sources might not permit the implementation to all projects. An MCDM approach has been defined here and utilized to an actual being project institute. In this research different criteria have been used such as quantitative \& qualitative which are constructive (positive) and destructive (negative). The Delphi approach was employed to convert the qualitative to quantitative criteria by using the one to nine (1 - 9) magnitudes. TOOPSIS manner helped for computing each project weight for assessing and ranking project priorities.

\section{CONCLUSION}

A real-life example in an industrial field was demonstrated, amongst five projects with respect to four criteria, afterwards applying TOPSIIS technique, the ranking of projects alternatives concerning its priorities and its weights will be :

\section{Project $3>$ Project $1>$ Project $4>$ Project $5>$ Project 2 .}

This means that the dairy factory is the best proposed small project which has the highest weight according to expert evaluations of the criteria for the project.

\section{REFERENCES}

[1] Javad Dodangeh, Majid Mojahed, Rosnah bt Mohd Yusuff,"Best Prject Selection by Using of Group TOPSIS Method", International Association of Computer Science and Information Technology, Spring Conference, 2009

[2] James J. Jiang, Gary Klein, "Project Selection Criteria by Strategic Orientation", Information \& Management , no.36, pp. 36-75,1999.

[3] Ivana Veselinovic, "Multi Criteria Methods And Models For Decision Making In Public Procurement", University of Nis, Faculty of Economic, vol. 11, no.3,pp.261-279,Dec.2014.

[4] A. Ishizaka, Ph. Nemery," Multi-Criteria Decision Analysis: Methods and Software", First Edition, John Wiley \& Sons, Ltd, 2013

[5] F. Mirmohammadi, G. Khorasani, A. Tatari, A. Yadollahi., H. Taherian, H. Motamed, S.Fazelpour, M. Khorasani, M. Reza Maleki Verki,"Investigation of Road Accidents and Casualties Factors with MCDM Methods in Iran", Journal of American Science, vol.9, no. 7,pp. 11-20,2013

[6] P. Kumar, "Integrated Project Evaluation And Selection Using Multiple Attribute Decision Making Technique", The International Journal Of Production Economics,vo.1, no. 3,pp. 90-103, Oct. 2005.

[7] S. Opricovic , G. Tzeng, "Compromise Solution By MCDM Methods: A Comparative Analysis Of VIKOR And TOPSIS", European Journal of Operational Research, vol. 1,no. 56, pp. 445-455,2004

[8] Muhammad Zulqarnain, Fazal Dayan, "Choose Best Criteria for Decision Making Via Fuzzy TOPSIS Method", Mathematical and Computer Science. Vol. 2, No. 6, pp. 113-119, 2017 